\title{
Desafíos de la pastoral juvenil latinoamericana frente a estructuras de corrupción: de una pastoral liberadora a una pastoral regeneradora
}

\author{
Carlos Castillo MatTasoglio* \\ Pontificia Universidad Católica del Perú (Perú) \\ ccastillomattasoglio@gmail.com
}

\begin{abstract}
Resumen
El artículo se sitúa ante los nuevos contextos que los jóvenes viven en América Latina, especialmente, considerando las estructuras de corrupción ante lo cual los jóvenes son más vulnerables por su condición de búsqueda de espacios de desarrollo y crecimiento social. Esta situación, plantea nuevos retos para la Pastoral Juvenil latinoamericana teniendo en cuenta que la misma institución eclesial no ha estado ajena a situaciones de corrupción. A través de un análisis documental, desde las Escrituras, pasando por cuatro de las Conferencias Episcopales Latinoamericanas, el artículo pretende desarrollar la tensión entre jóvenes, sociedad y pastoral juvenil, para finalmente presentar una propuesta que se fundamenta en un proceso juvenil de cinco décadas que transita desde una pastoral liberadora a una pastoral regeneradora, donde los sujetos jóvenes rotos buscan renacer en nuestra América Latina.
\end{abstract}

Palabras claves: Pastoral juvenil, jóvenes, corrupción, pastoral regeneradora, jóvenes rotos.

\section{Challenges of Latin American youth ministry in the face of corrupt structures: from a liberating pastoral to a regenerative pastoral}

\begin{abstract}
s
The article is set against the new contexts that young people live in Latin America, especially considering the structures of corruption to which young people are more vulnerable because of their search for spaces of development and social growth. This situation poses new challenges for Latin American Youth Ministry bearing in mind that the Church institution itself has not been unaware of situations of corruption. Through a documentary analysis, from the Scriptures, through four of the Latin American Episcopal Conferences, the article aims to develop the tension between young people, society and youth pastoral, to finally present a proposal that is based on a youth process of five decades that It goes from a liberating pastoral to a regenerative pastoral, where the broken young subjects seek to be reborn in our Latin America.
\end{abstract}

Key words: Youth ministry, youth, corruption, regenerative pastoral, young people broken.

* Doctor in Sacra Theologia por la Pontificia Universidad Gregoriana de Roma. Theologia: Spec in Th. Dogmatica por la Pontificia Universidad Gregoriana de Roma. Actualmente, es académico del Departamento de Teología de la Pontificia Universidad Católica del Perú. 


\section{INTRODUCCIÓN}

El artículo pretende plantear los nuevos retos que debe asumir la Pastoral Juvenil latinoamericana teniendo en cuenta los nuevos contextos. Una transformación esencial a tomar en cuenta, es el que está produciendo la primera crisis global de las finanzas que, según Magatti (2017) han comenzado a redefinir los objetivos del mundo financiero global que afectan directamente a la juventud. Ellos, pasarán de consumistas a constituirse para el sistema, en una juventud sometida a la esclavitud de un reordenamiento neotaylorista del mundo, ya que, los productos que se fabrican, cada vez tendrán menos componente de trabajo humano, permiten poca proporción de ganancia. Harari (2016), plantea que la sustitución de humanos por algoritmos, está desarrollándose hasta el punto de expulsar no solo a trabajadores no calificados como cajeros, camareros, panaderos, obreros de construcción, sino incluso a profesionales calificados.

Los jóvenes necesitan desarrollar estrategias de sobrevivencia a un sistema que configura instituciones corruptas para alcanzar sus fines, evadiendo toda legislación laboral en pos de las ganancias, y cuyas víctimas más jugosas para los grandes financistas son los jóvenes. Lo peor es que parece que nadie puede defenderse de esta vorágine capitalista y es por eso que las instituciones privadas, estatales y eclesiásticas, corren el peligro de rendir pleitesía al sistema imperante. Es por esto que, hasta las instituciones, aparentemente más nobles, se corrompen en el sentido que no cumplen las funciones para los cuales han sido edificadas. Así, la opción preferencial por los jóvenes que declaró Medellín hace 50 años, y la Pastoral juvenil que de allí surge (CELAM, 1968), hoy se enfrenta a nuevos desafíos, donde los jóvenes parecen ser las víctimas más vulnerables de la corrupción de las instituciones.

Ante esta situación, los jóvenes podrían buscar un lugar de esperanza con la Iglesia latinoamericana, sin embargo, según Silva (1993), las conceptualizaciones y definiciones de la realidad y del mundo juvenil propuestas en las conferencias latinoamericanas, no se corresponden con los hechos ni con las acciones posteriores. Así, el discurso de la jerarquía eclesial no habría generado los mecanismos efectivos que propicien la trasformación de las situaciones que denuncian proféticamente. Sin embargo, se afirma, parecen haber planteado válidas observaciones de la realidad que han terminado en un cuadro de respuestas formalistas y poco efectivas. Es decir, a la denuncia profética de la Iglesia no ha seguido la "conversión" de las estructuras, con lo cual persiste la "situación de pecado" en el continente latinoamericano. Esto, lejos de absolver a la iglesia, la cuestiona en sus raíces más profundas por su grado de connivencia con el "stablishment 
latinoamericano", por lo que la iglesia también ha caído en los tentáculos de la corrupción perdiendo el horizonte de su misión (Francisco, 2018a).

Esto se nota claramente respecto a la juventud, donde se observa el deseo de pasar de la afirmación afectiva a la efectiva, pero no se plasma suficientemente en una pastoral de juventud durable a largo plazo, que comprenda la especificidad de la situación juvenil y la enfrente con una respuesta lúcida capaz de ser vehículo institucional firme que constituya referencia fundamental para la vida de todo joven latinoamericano. Así, surgen intuiciones espontáneas de fe en los jóvenes, aunque no corran directamente por las formas cristianas o católicas, están desafiando a una manera nueva de percibir lo religioso, con sus ambigüedades, pero también con sus aportes. El derrumbe de las formas conservadoras de vivir la fe que han vuelto en los últimos años, y la urgencia de encontrar espacios de reconstitución humana, favorece la experiencia nueva de una fe que crece desde sus identidades culturales y generacionales. Se parecen abrir las bases para una nueva manera de creer, en medio del agotamiento de un mundo y una experiencia de fe que declina inexorablemente.

Ante esta realidad, la Iglesia Católica parece estar comenzando otra vez de cero, si bien sus opciones declarativas se mantienen y hoy parecen reforzarse a través de la convocatoria del Sínodo de los Obispos sobre los jóvenes, ellos han podido expresar las heridas provocadas por diversos escándalos de la institución eclesial y piden transformaciones:

Los jóvenes destacan que, con respecto a la promoción de la justicia, la imagen de la Iglesia se presenta "dicotómica": por un lado, quiere estar presente en la historia al lado de los últimos, por el otro todavía tiene mucho por hacer para extirpar situaciones, inclusive graves y generalizadas, de corrupción, que la hacen correr el riesgo de conformarse al mundo en lugar de ser portadora de una alternativa inspirada en el Evangelio (Sínodo de los Obispos, 2018: n. 28).

$\mathrm{Al}$ respecto, los mismos padres sinodales se cuestionan: “Cómo puede un joven ser un profeta de la esperanza en un mundo donde reinan la corrupción y la injusticia?" (Sínodo de los Obispos, 2018: n. 78). Ciertamente, se necesitan nuevas formas de acompañamiento pastoral, de allí que nuevas voces de sacerdotes, teólogos, religiosas y laicos que acompañan la fe juvenil presentan algunos jalones nuevos de reflexión. Baste citar varios intentos que expresan esta exigencia de renovación tanto en Latinoamérica, en el caso de Espitia (2008) que propone trabajar fortaleciendo la espiritualidad juvenil; también los jesuitas que han avanzado en ideas renovadas de diálogo con las culturas juveniles (Atilano, 2004). Desde otros horizontes distintos a nuestro continente, de Bélgica llega el trabajo 
acucioso de Bacq y Theobald (2011) donde realizan la propuesta de una pastoral del engendramiento; y desde Italia un trabajo que llama a redefinir toda la pastoral juvenil desde el desafío antropológico de los jóvenes $(\mathrm{Cu}-$ rro, 2011; Rossano, 2017). Signos todos de que algo importante ha de ocurrir en la pastoral para estar a la altura del desafiante mundo juvenil actual.

En razón a estas nuevas propuestas, este artículo busca contribuir a configurar una pastoral latinoamericana donde la realidad juvenil propone un desafío cualitativo proveniente de la vivencia de un mundo afectado por la epidemia de la corrupción. Para aportar a la reflexión de una renovada pastoral juvenil, el texto propone iluminar desde la Escritura como, en tiempos de Jesús, los jóvenes son víctimas de la corrupción de las estructuras sociales y eclesiales; posteriormente, conviene hacer una revisión documental de las Conferencias Episcopales latinoamericanas y lograr entender cuál ha sido la evolución del pensamiento episcopal para tomar decisiones a favor de una constitución realmente efectiva en los tiempos que corren de la Pastoral de Juventud y así plantear una propuesta de una pastoral liberadora a una pastoral regeneradora, donde la comunidad eclesial pueda acompañar a los jóvenes, y permitirles constituirse en nueva esperanza para América Latina.

\section{LOS JÓVENES COMO VÍCTIMAS DE LA CORRUPCIÓN EN LAS ESTRUCTU- RAS SOCIALES Y ECLESIALES EN TIEMPOS DE JESÚS}

Para abordar el tema de los jóvenes en tiempo de Jesús, es preciso situar el peso de los problemas históricos de Israel en el mundo que vivió Jesús. Uno de los aspectos, según Castillo (2003) es el desarrollo y decadencia del judaísmo posterior al exilio. Israel se propuso en esta época regenerarse como pueblo a través de una vuelta a la ley, al templo, y a un gobierno estructurado de sacerdotes precedidos por el Sumo Sacerdote y muy lejano al reino político que antecedió al exilio (Tassin, 1987). En efecto, el judaísmo no solo había repetido, sino incluso deformado la vida de Israel, hasta el punto de degenerar en un proceso de diseminación y disolución como pueblo. Este proceso culminará el año 70 con la invasión y destrucción de Jerusalén y la desaparición de Israel.

La decadencia del gobierno sacerdotal, se expresó principalmente en una situación de derrota y de dependencia de Israel respecto a las sucesivas potencias persa, griega y romana que pusieron en crisis el espíritu con que fue constituida la época postexílica. Sobre todo, las grandes esperanzas que se habían abierto con la reconstrucción del templo, y sobre todo con el triunfo de los Macabeos durante la guerra santa contra los griegos en defensa de la religión hebrea, se desvanecieron a medida que todo sacerdote 
llegado al poder cedía cada vez más al proceso de helenización, generando una adaptación sincretista que desdecía toda la aparente solidez exterior del culto del templo (Saulnier, 1985). Esto no era algo sin consecuencias sociales y humanas, porque dicho sincretismo sacerdotal redundó en un ritualismo indiferente al sufrimiento y pobreza del pueblo, que por lo demás acentuó la pobreza generada por los dominadores extranjeros, ya que para mantener el complejo religioso se recurrió permanentemente a los impuestos de diversa índole y se oprimió de múltiples formas a la gente sencilla, encubriéndose todo dentro del velo de lo religioso. A su vez, el pesimismo respecto a las posibilidades de salidas, los marcos de interpretación cada vez más aculturados a los estilos de las culturas dominantes persa, helénica y latina, y la emergencia del lenguaje simbólico como medio para comprender la complejidad de las situaciones, fueron en crecimiento (Castillo, 2003).

En Israel algunos creyentes intentaron expresar por escrito esta crisis y dieron lugar a reflexiones que actualizaron el sentido de la revelación para este tiempo. Así, por ejemplo, Qohelet expresa la crisis de la sabiduría tradicional ante la incursión galopante de Alejando Magno que invade con su poder todo el orbe (Vilchez, 1994). Job expresa eso mismo desde el punto de vista de los inocentes que sufren la situación (Gutiérrez, 1986). El libro del Eclesiástico reúne los textos más simples, los dichos populares, en una época de derrota (Vilchez, 1995).

El libro del Génesis en sus once primeros capítulos expresa bien la gran pregunta de la época, ¿porque el mal es tan persistente?, ¿que lo causa? ¿porque estamos tan mal y tan afligidos y nada soluciona esta decadencia? (Castillo, 2003). Por su parte, sectores espiritualistas que usan lenguaje apocalíptico propondrán una respuesta evasiva: el mal viene de ángeles malos que pecaron y que manipularon al ser humano, en correspondencia hebrea al mito de las almas caídas y encarceladas de Platón y al general pesimismo antropológico de los griegos. Daniel y el Génesis dan otra respuesta: el mal se debe a un acto irresponsable del ser humano, condicionado claro está, pero una decisión de la voluntad. De allí que la esperanza estará no en otros ángeles buenos que bajen a hacer el bien, sino que viene del Hijo del hombre, enviado por Dios pero que es un ser humano responsable que respeta y obedece a la gracia (Pikaza, 1993).

Siguiendo este proceso de reflexión, acerca del sentido del creyente en una decadencia cada vez mayor, un judío alejandrino escribe el libro de la Sabiduría, en el que se propone la suerte triunfal de los justos ante la permanente y galopante corrupción del mundo helenista (Busto, 1992). Este libro es el último en escribirse antes de Jesús y empalma con su época, probablemente, un contemporáneo suyo. Pretende cuestionar el fatalismo y 
alentar a los israelitas justos a seguir afirmándose como tales a pesar de la adversidad, de tal manera que no se dejen tentar por la orgía de los injustos.

Pero es curioso que escoge como figura ejemplar la imagen del "joven justo", refiriendo indirectamente a Henoc, el menor de los patriarcas prediluvianos que tiene 365 años, es decir un año de años, y que Sabiduría coloca como alguien justo situado en medio de la corrupción, pero sacado de la tierra joven, debido a que Dios tiene para ellos reservada la felicidad y quiere evitar que sean corrompidos. La muerte del justo joven, muerte por tanto prematura, es motivo de aliento para el creyente como se lee en Sabiduría 4, 7-20:

El justo, aunque muera prematuramente, halla el descanso. La ancianidad venerable no es la de los muchos días ni se mide por el número de años; la verdadera canicie para el hombre es la prudencia, y la edad proyecta, una vida inmaculada. Agradó a Dios y fue amado, y como vivía entre pecadores, fue trasladado. Fue arrebatado para que la maldad no pervirtiera su inteligencia o el engaño sedujera su alma; pues la fascinación del mal empaña el bien y los vaivenes de la concupiscencia corrompen el espíritu ingenuo. Alcanzando en breve la perfección, llenó largos años. Su alma era del agrado del Señor, por eso se apresuró a sacarle de entre la maldad. Lo ven las gentes y no comprenden, ni caen en cuenta que la gracia y la misericordia son para sus elegidos y su visita para sus santos. El justo muerto condena a los impíos vivos, y la juventud pronto consumada, la larga ancianidad del inicuo. Ven la muerte del sabio, mas no comprenden los planes del Señor sobre él ni por qué le ha puesto en seguridad; lo ven y lo desprecian, pero el Señor se reirá de ellos. Después serán cadáveres despreciables, objeto de ultraje entre los muertos para siempre. Porque el Señor los quebrará lanzándolos de cabeza, sin habla, los sacudirá de sus cimientos; quedarán totalmente asolados, sumidos en el dolor, y su recuerdo se perderá. Al tiempo de dar cuenta de sus pecados irán acobardados, y sus iniquidades se les enfrentarán acusándoles.

Existe aquí pues la imagen del joven justo que persevera en medio de la corrupción. Es un deseo del autor que la situación que invade al judaísmo postexílico se resuelva manteniéndose los israelitas justos. Y quienes están en mayor peligro son los jóvenes, principalmente tentados de helenización.

Esto configura una situación especial. En este libro se da la imagen de que los jóvenes han de permanecer puros para que Dios les entregue una misión. Si consideramos otros casos del Antiguo Testamento en que al joven Dios les da su misión básicamente siendo ellos jóvenes, sin exigencias previas, los libros deuterocanónicos acentúan el aspecto de la purificación y de la prudencia previa como condición de recepción de una misión. Es más, su misión es mantenerse prudentes para ser puros. Hay algo así como un modelo, un mito de lo que debe ser el joven para contrarrestar la 
degeneración. Casos paralelos son el de la Joven Susana en el libro de Daniel, o las recomendaciones a los jóvenes en el Eclesiástico (Castillo, 2003).

En una época de quiebra de valores, la carga va dirigida a educar a los jóvenes en la sabiduría, la prudencia y la pureza, contra el mundo corrompido y que en su corrupción se ríe de los pobres y los explota. Esto es responsabilidad urgente y necesaria, la juventud debe educarse en valores y superar el mundo anciano decadente y así hacerse de los pobres.

Un punto, sin embargo, no cuestionado en las diversas corrientes del judaísmo es el asunto de la extrema justicia del justo y por ende de la violencia. Al parecer ningún grupo judío consideraba que pudiera prescindirse del celo por la ley, y por ello mismo del uso de la violencia santa para actuar la justicia, si era necesario. Un zelotismo cultural fue generalizándose poco a poco hasta llegar a los diferentes grupos judíos de la época de Jesús, en que nadie se excluía de esta posibilidad, a pesar de los diversos acentos con que se presentaba. Incluso el autor del libro de la sabiduría y Juan el Bautista encarnan ánimos de celo violento y de acento en la justicia que envuelve a la misericordia (Beauchamp \& Vasse, 1992). Esto es importante porque el modelo con que se pretende formar a los jóvenes es el del joven justo, es decir, celoso por la ley y en cierto modo violento. Es el ideal al que se aspira con toda la buena intención de la tradición judía.

Pero hay algo curioso. Los jóvenes de la época de Jesús no parecen ser personas capaces de caminar por exigencias tan fuertes de perfección y de firmeza. Tenemos un contraste con la tradición pre-exílica donde Dios llama al joven sin exigencias previas y le confía una misión, mientras que, en el Nuevo Testamento, parecen haber exigencias previas. ¿Serán tal vez las mismas que coloca la tradición postexílica de los deuterocanónicos, es decir, un proceso previo de purificación, y de conocimiento de la prudencia, como misión o para luego recibir una misión? (Castillo, 2003).

El Nuevo Testamento y Jesús, pareciera que partieron desde otras consideraciones. Para visualizar este aspecto se analizará un texto muy significativo que podría responder estos cuestionamientos. Se trata de Mateo 11, 16-19 (y Lc 7, 31-35). Se analizará la versión de Mateo:

¿Pero, con quién compararé a esta generación? Se parece a los chiquillos que, sentados en las plazas, se gritan unos a otros diciendo: "Os hemos tocado la flauta, y no habéis bailado, os hemos entonado endechas, y no os habéis lamentado". Porque vino Juan, que ni comía ni bebía, y dicen: "Demonio tiene". Vino el Hijo del hombre, que come y bebe, y dicen: "Ahí tenéis un comilón y un borracho, amigo de publicanos y pecadores". Y la Sabiduría se ha acreditado por sus obras. 
Este texto es una contestación a los discípulos de Juan que preguntaron a Jesús: “¿eres tú el que ha de venir o debemos esperar a otro?” (Lc 7, 19; Mt 11, 3). Antes de esta contestación hay una respuesta primera con sus obras para con los pobres y ha terminado diciendo: "Y dichoso aquel que no se escandalice de mí” (Mt 11, 6; Lc 7, 23). Luego ha elogiado a Juan como el más grande, para proponer la novedad del Reino, que consiste en que el más pequeño de este es más grande aún que Juan. Es decir, Reino que se ha inaugurado sobrepasa abundantemente las categorías de Juan por más que las de Juan fueran buenas.

En forma sumaria Jesús va a hablar de su generación (en Mateo) y de "los hombres" de su generación (en Lucas) haciendo un juicio sobre ellos: son un público descontento, pesimista, que nada considera algo interesante, son en bloque un grupo escéptico, desmotivado, que excluye cualquier posibilidad de novedad y que no entiende los signos que se les presentan, permaneciendo encerrados en sus categorías.

Pero Jesús en vez de decirlo con estas palabras usa una comparación: "Con quien compararé a esta generación?" (v.31). La comparación que utiliza para hablar de los contemporáneos mayores suyos es nada menos que un hecho de la vida cotidiana de los jóvenes de su tiempo. Jesús siempre está atento y conoce lo que sucede en su tiempo, sus comparaciones revelan que está no solo de cara al Padre sino también de cara a la realidad de su pueblo. Pues bien, su comparación se basa en la observación de la actitud general de los "chiquillos" de su tiempo. ¿Que ve en ellos? Ve su pesimismo, su escepticismo, su falta de ánimo tras de observarlos sentados en las plazas reprochándose mutuamente su falta de acogida a la iniciativa de bailar o de lamentarse según hayan tocado música alegre o triste (Castillo, 2003).

Quiere decir que Jesús para poner en cuestión a toda una generación de pesimistas, escépticos y cerrados, usa como comparación el resultado que han obtenido en los jóvenes. Es como decirles, ustedes se parecen a su resultado. Porque no "lloran" con Juan ni "bailan" con Jesús, por el contrario, los malinterpretan diciéndole a uno que tiene demonio y al otro que es un borracho y comilón, amigo de publicanos y pecadores. Y acota: "Y la Sabiduría se ha acreditado por sus obras". Es decir, de nada valen los apelativos contra Jesús porque sus obras atestiguan que se trata de la Sabiduría divina en acción. Con esto Jesús incluye en la crítica al mismo Juan y a toda la generación de su época.

¿Podríamos hacer una inversión? si la generación contemporánea de Jesús, es comparable a los jóvenes pesimistas, ¿'se podría decir acaso que los jóvenes pesimistas se parecen a la generación que les infundio el pesimismo? (Castillo, 2003). El texto no lo dice, pero hay otro texto que nos induce a suponerlo. Se trata de Mc 9, 14-29, en el que Jesús llama "generación incrédula" a sus propios discípulos, y desata su indignación contra ellos 
(¡Hasta cuando estaré con Uds. hasta cuando tendré que soportarlos!) hasta el punto de que en Lucas 9, 41 les llama incluso "generación incrédula y perversa" y en otras traducciones corrupta y pervertida. Por tanto, los jóvenes durante la vida pública de Jesús, son víctimas de la corrupción de generaciones anteriores que frente al poder de los pueblos opresores transaron su fe, generando una sociedad sin esperanza.

2. LOS JÓVENES FRENTE A LAS ESTRUCTURAS DE PECADO DENUNCIADAS POR LAS CONFERENCIAS GENERALES DEL EPISCOPADO LATINOAMERICANO

En este apartado se desarrollará el tema de los jóvenes y las estructuras de pecado a partir del análisis documental de las Conferencias Latinoamericanas de Medellín, Puebla, Santo Domingo y Aparecida. Partiendo del hecho que todas las Conferencias cuando se refieren al cuidado pastoral de los jóvenes, inician su reflexión a partir de la etapa del "ver" del método ver, juzgar y actuar. De esta manera, realizan un discernimiento del contexto del joven en situación refiriéndose a las estructuras de pecado, que en razón del tema a tratar se podrían leer como estructuras corruptas, que afectan la vida y el desarrollo de los jóvenes latinoamericanos. De hecho, el Sínodo, uno de los aspectos que recogió de las inquietudes del mundo de los jóvenes es la corrupción como "una plaga que afecta a muchas sociedades en sus cimientos" (Sínodo de los Obispo, 2018: n. 59).

\subsection{Medellín}

La Conferencia de Medellín (CELAM, 1968) intenta no solo captar sino también apreciar el valor de los jóvenes de su época. Percibe algo nuevo en esa juventud: encontrarse marcada por su despertar a la conciencia social. Con ello la valora como sujeto emergente y consciente que adquiere protagonismo en la vida social injusta y conflictiva de América Latina. Aquella juventud de los años 60-70 vivía en la situación explosiva del continente que la inducía a un protagonismo relevante.

Por ello llama a la iglesia latinoamericana a abrirse de modo urgente al asunto de la juventud. Así, como se coloca escuchando el clamor de los pobres, Medellín (CELAM, 1968) se abre a los interrogantes y búsquedas de este nuevo sujeto histórico, y a su capacidad de transformación. Lo entiende cualitativamente como una gran fuerza de presión, y no solo lo ve como el sector más numeroso. Incluso ve aspectos interesantes en sus capacidades críticas y de rebeldía. En efecto, lo percibe como un nuevo cuerpo social que tiene propias ideas y valores, que porta un dinamismo 
interno, que rechaza los valores negativos de la tradición, aunque alerta contra cierta tendencia al idealismo que niega la realidad, a inconformismo, y a prescindir absolutamente del pasado.

La valoración de estos signos de crítica radical en la juventud parte del reconocimiento de la crisis en todos los órdenes en que han entrado las sociedades latinoamericanas, donde se han ido negando grandes valores, y por lo cual los jóvenes rechazan un estilo de vida falto de autenticidad, mostrando así una insatisfacción que crece cada día. En efecto, Medellín (CELAM, 1968) aprecia que la juventud reclama cambios profundos y rápidos que garanticen una sociedad justa. Reconoce sin embargo que hay tres sectores que están fuera de esta tendencia positiva a la radicalidad, los jóvenes pasivos que sucumben las formas burguesas de vida, los jóvenes activos que se hacen proclives a la secularización y a la sociedad pluralista y aquellos que se dejan tentar por la violencia extremista.

En cuanto a la relación con la Iglesia, Medellín (CELAM, 1968) percibe un problema de lejanía de la Iglesia hacia los jóvenes que habla un lenguaje de predicación y escrituras que les resultan extraños, donde los pastores tienen absoluta responsabilidad. Por parte de los jóvenes, estos no se consideran parte de la iglesia y la perciben sólo como jerarquía.

Por otro lado, dan cuenta también de una iniciativa comunitaria de los jóvenes en la iglesia. Es decir, nota una tendencia nueva a formar comunidades por parte de ellos que les permiten una mayor personalización, conciencia de sí mismos y creatividad, buscando vivir con mayor autenticidad y sinceridad, participando activamente de la vida social y eclesial y asumiendo nuevas responsabilidades y funciones en la iglesia.

\subsection{Puebla}

En el Documento de Puebla (CELAM, 1979) hay una sección especial dedicada al tema de la juventud; pero también hay muchas indicaciones sobre los jóvenes en todo el documento. En la parte dedicada al "ver" describe de modo muy interesante lo que ocurre con los jóvenes de su momento histórico, más marcado por un mayor desarrollo de los desafíos de la urbanización y las ciudades.

Algo diferente de lo que se señaló en Medellín pero en la misma línea, Puebla afirma desde sus inicios "nuestro pueblo es joven" (CELAM, 1979: n. 20) y luego "tenemos una población mayoritariamente joven" (CELAM, 1979: n. 71) previendo que tendrá dificultades futuras de encontrar trabajo, pero subraya sobre todo que los jóvenes están sometidos a un mundo adulto que les impide ejercer el papel normal de transformación que tiene toda juventud, como lo había señalado Medellín, desembocando en caminos diversos de radicalismo o indiferencia, que les hace ser manipulados o 
ilusionados sin tener la base formativa adecuada para realizar su misión en el cuerpo social. Puebla avizora una tendencia al deterioro de la juventud, por conflictos generacionales con el mundo adulto, "la civilización de consumo, una cierta pedagogía del instinto, la droga, el sexualismo, la tentación de ateísmo" (CELAM, 1979: n.1171).

Así, Puebla (CELAM, 1979) reconoce y sitúa a los jóvenes al interior de una sociedad mayoritariamente pobre y al joven como participante concreto de esa sociedad y condición marginada. Es más, contiene una visión de la realidad desde el punto de vista cristológico, ya que coloca a los jóvenes entre los rostros sufrientes de los pobres en América Latina: "rostros de jóvenes, desorientados por no encontrar su lugar en la sociedad; frustrados, sobre todo en zonas rurales y urbanas marginales, por falta de oportunidades de capacitación y ocupación” (CELAM, 1979: n.32). Los jóvenes se instalan en el segundo lugar después de los niños, en este profundo y hermoso texto acerca de los rostros sufrientes de Cristo a cuya escritura contribuyó con tanta sensibilidad Mons. Germán Schmiz, obispo auxiliar de Lima.

Se nota, sin embargo, un temor de los obispos latinoamericanos a que los jóvenes caigan en manipulación extremista de protesta o en indiferencia y relajo, influidos por la sociedad. De allí que intente una especie de recuperación de la juventud en perspectiva humanista y cristiana, más allá de la protesta, para ayudarla a canalizar sus capacidades y fuerzas participativas en la construcción social; por ello en el Mensaje de Puebla que dirigen los obispos a la Juventud dicen:

Invitamos cordialmente a los jóvenes a vencer los obstáculos que amenazan su derecho de participación consciente y responsable en la construcción de un mundo mejor. No les deseamos la ausencia pecaminosa de la mesa de la vida, ni la triste entrega a los imperativos del placer, del indiferentismo o de la soledad voluntaria e improductiva. Ya pasó la hora de la protesta traducida en formas exóticas o a través de exaltaciones intempestivas. Vuestra capacidad es inmensa. Ha llegado el momento de la reflexión y de la plena aceptación del desafío de vivir, en plenitud, los valores esenciales del verdadero humanismo integral (CELAM, 1979: n. 6).

Es una pérdida, respecto a Medellín, el que se vean los problemas sociales de los jóvenes, sin soluciones sociales y civiles posibles y, otra merma es que la Iglesia no parece querer modificarse en relación a ellos, sino que parece permanecer la misma, aunque preocupada por los problemas urgentes de los jóvenes en la sociedad.

De aquí que el hándicap de Puebla (CELAM, 1979) estará en adelante en el modo como la Iglesia realiza una evangelización y proyecto pastoral 
con los jóvenes: o anchando internamente la propia Iglesia, haciéndose partícipe de sus búsquedas en vistas del Reino de Dios, o adscribiendo a los jóvenes a un orden ya preestablecido que asocia a los jóvenes, pero no los escucha, que los forma según un criterio predeterminado, pero no en diálogo con ellos. Por ello en el "ver" podemos delinear la valoración que Puebla hace de la situación real de los jóvenes de la década de los 80 .

Los obispos reunidos en Puebla consideran a América Latina como todo un pueblo joven que aspira a superarse en medio de la pobreza. Más precisamente es desde su condición joven que ha aprovechado las oportunidades para superarse y reivindicarse en forma justa. Sin embargo, en esta situación real la pobreza y la marginalidad continúan a 10 años de Medellín y en ella los jóvenes no encuentran lugar en la sociedad y están frustrados en zonas rurales y marginales por falta de oportunidades y capacitación y ocupación.

Puebla (CELAM, 1979), perciben positivamente el inconformismo y sensibilidad social de los jóvenes que los compromete a cambiar radicalmente la sociedad, valoran que todo lo cuestionen y el espíritu de riesgo que la lleva al compromiso y a situaciones radicales, así como su fuerte sensibilidad ante los problemas sociales, aprobando su rebeldía ante la hipocresía de la sociedad y sus antivalores.

Pero comienza a percibir en los jóvenes de los 80 signos de desorientación. A Puebla (CELAM, 1979) le preocupa el ambiente adulto incoherente y manipulador que los amenaza y que los desorienta, además de la sociedad de consumo, la pedagogía del instinto, la droga, el sexualismo, el ateísmo, la manipulación de la juventud en lo político y en el tiempo libre, especialmente vivida entre los que teniendo conciencia social y política, mantienen una falta de formación que los radicaliza y conduce a frustraciones, que llevan a la "pérdida de su capacidad dinamizadora" (CELAM, 1979: n. 1170).

De todos modos, Puebla reconoce la diversidad de jóvenes nacida de las situaciones desiguales en que viven: mujeres jóvenes en crisis de identidad por liberación y por machismo; los que tienen una situación cómoda que desarrollan con normalidad; los que están en condiciones de pobreza (indígenas, campesinos, mineros) que se ven obligados a trabajar como los mayores; los jóvenes estudiantes que viven en la inseguridad de futuro empleo y con falta de orientación vocacional que los lleve a un futuro. Y aquí los que no esperan - defraudados por líderes - y los que esperan desean construir la paz. 


\subsection{Santo Domingo}

El Documento de Santo Domingo (CELAM, 1992), a pesar de desordenar metodológicamente el ver-juzgar-actuar cambiándolo por el "juzgar-ver-actuar", tuvo una visión un tanto reducida de la realidad juvenil, aunque continúa la reflexión teológica sobre los jóvenes de los 90 . Al revés de Puebla que acentúa el "ver" de la situación social, aquí Santo Domingo ve a los jóvenes solo en función de la realidad pastoral, sin profundizar en las particularidades de los jóvenes.

En efecto, existe aquí una cierta renuncia a identificar explícitamente y de forma precisa los problemas, y a un diagnóstico de la situación. Más bien, tenemos una visión del joven desde el punto de vista intimista e intraeclesial, que evita responder a los retos que estos traen, y dándoles lo que no parecen estar buscando. Esto empieza a constituir un problema que ya en Puebla se notaba, la iglesia se preocupa por los jóvenes, pero sin cambiar ella. De todos modos, algunos elementos aparecen en esta "agenda" que fue Santo Domingo.

El documento (CELAM, 1992), hace una descripción superficial pero verdadera del deterioro humano y social en que han entrado los jóvenes de América Latina desde los 90: de sujetos han pasado a ser víctimas pasivas, reconociendo a los jóvenes como heridos del empobrecimiento, manipulación social, falta de empleo, educación que no responde a exigencias, guerrilla, pandillas, prostitución, alcoholismo, abusos sexuales, adormecimiento por los medios, pragmatismo.

En segundo lugar, reduce el tema juvenil a un problema subjetivo importante pero no el único que tienen los jóvenes: la emergencia del problema central de la maduración afectiva de adolescentes y jóvenes. Este centrarse en lo subjetivo del joven comienza a ocupar el lugar central, y al parecer con cierta razón, ya que en todo lugar de América Latina se empieza a sentir que el sujeto histórico, joven, se ha debilitado y se estaría viviendo un generalizado debilitamiento de la subjetividad social y personal. De modo que los jóvenes que reaccionan ante los problemas de la sociedad existen todavía, pero son solo algunos pocos quienes rechazan el consumismo, la corrupción, tienen sensibilidad por los pobres y sus debilidades, y se insertan en la sociedad generando espacios de participación democrática.

A pesar de esta labilidad juvenil, Santo Domingo afirma como un desafío de la realidad que estos jóvenes les reclaman a sus pastores y a la Iglesia "acompañamiento espiritual" y "apoyo en sus actividades" (CELAM, 1992: n. 112). La debilidad de los jóvenes también se presenta en el hecho de que los jóvenes empiezan abandonar la iglesia, el ausentismo en 
grupos, comunidades y movimientos, y falta de compromisos firmes y duraderos de acción misionera y apostólica.

El valor de esta descripción intimista e intra-eclesial es que muestra los inicios de lo que ocurrió después de 1992, es decir un proceso de resquebrajamiento de los jóvenes, y la constitución no de un sujeto histórico sino la de un "sujeto roto", expresión acuñada en la reunión de asesores de Huancayo en Perú.

De todos modos, veremos que la reacción de la Iglesia ante esta subjetividad rota y ante los signos de abandono conducirán a la comunidad eclesial a dar respuestas diferentes según las visiones teológicas que se manejen. La Iglesia posterior a Santo Domingo logró sólo temporalmente ponerse a la altura de la vuelta al despertar juvenil, que luego fue frustrado por acciones pastorales indebidas en muchos lugares de América Latina.

\subsection{Aparecida}

La primera parte del documento de Aparecida: "La vida de nuestros pueblos hoy" (CELAM, 2007) presenta una mirada de la realidad latinoamericana desde el punto de vista de los discípulos y misioneros, es decir, una mirada creyente de la realidad. En ella, y en las demás partes hay, como fue en las conferencias anteriores, referencias a la realidad de la juventud. El documento presenta la visión de la realidad de los jóvenes como un conjunto de desafíos que impulsan a la Iglesia a tener que responder, encaminado a un solo objetivo: mostrar los desafíos que una pastoral juvenil debe enfrentar para conseguir formar a jóvenes discípulos y misioneros que logren dar vida en Cristo.

El Documento de Aparecida percibe al joven en la realidad de América latina, lo sitúa integrado a ella, específicamente en la realidad de pobreza, hasta el punto de mencionarlo en la lista de los "rostros sufrientes de Cristo" en nuestros pueblos; los ubica en tercer lugar, después de los indígenas y afrodescendientes, y después de las mujeres. (CELAM, 2007: n. 65) El sufrimiento de los jóvenes es visto sobre todo en cuatro dimensiones: receptores de educación de baja calidad; ausencia de oportunidades de progresar en sus estudios; ausencia de oportunidades para entrar en el mercado de trabajo; ausencia de oportunidades para desarrollarse y constituir familias.

Uno de los elementos que enriquece la visión del rostro sufriente de Cristo en los jóvenes es lo que produce en ellos la pobreza, Aparecida detecta que ello se traduce en violencia para la vida de los jóvenes, en especial para las "mujeres adolescentes" (CELAM, 2007: n. 445). Otra manifestación de la violencia es la comercialización de la droga que involucra cada vez más a la juventud, presentándose como una salida desesperada a 
la falta de trabajo y educación. Con ello, en un continente estrecho de posibilidades para los jóvenes, la migración para encontrar trabajo en otros países y la movilidad humana, adquiere rostro juvenil.

Sobre la base del tema de la pobreza-violencia, el documento va a poner el acento en examinar las consecuencias y el significado que tienen para los jóvenes en el plano social, y muy especialmente en el cultural. Entre las consecuencias negativas, el documento de Aparecida (CELAM, 2007) señala una situación de permanente desarraigo y exclusión que conduce a un tipo de joven sin raíces culturales y cada vez menos profundo, que incluso impacta en el ámbito religioso. Además, existe un desplazamiento de la familia como protagonista de la formación del joven, con la consecuente ruptura de la transmisión inter-generacional, no habiendo ya la misma fluidez de comunicación de los valores tradicionales permanentes, donde la familia como lugar de diálogo inter-generacional y de solidaridad, se afecta profundamente, considerando que había sido uno de los vehículos más importantes de la transmisión de la fe Por su parte, surge un $m o d e l o$ de ser humano joven inclinado a la alucinación de pretendidos valores que lo ciegan, porque fomentan la satisfacción inmediata de sus deseos que los descontrola; surgiendo nuevas subjetividades carentes de profundidad, preocupadas sólo por el presente, individualistas y narcisistas, y sin referentes de valor.

Ahora bien, los obispos latinoamericanos también perciben aspectos positivos, como el hecho que los jóvenes son la mayoría de la población de América Latina y el Caribe. Por lo mismo, se constituyen en un enorme potencial para la realidad social de latinoamérica y para la Iglesia en ella, en su presente y en su futuro. Se puede ver allí una sensibilidad hacia la vocación de amistad y discipulado con Cristo, generosidad de entrega; convocación a ser centinelas del mañana en cuanto a comprometerse en la renovación del mundo según el Plan de Dios; no temen al sacrificio ni a la entrega de su propia vida; pero sí tienen temor a una vida sin sentido. Muestran generosidad ante los necesitados; capacidad de oposición a ideales y cosas engañosas; buscan el sentido de la vida que los abre al llamado particular de Cristo; tienen capacidad de comunicación del evangelio a sus propios hermanos jóvenes; capacidad de construir lazos de comunidad para la iglesia y la sociedad.

Desde esta realidad juvenil, se puede desprender que en Latinoamérica se han desarrollado nuevos sujetos y nuevas culturas donde la fragilidad e inestabilidad de las jóvenes víctimas, los vuelve grandes buscadores de sentido, lo que puede abrirlos a valores más profundos y a la Verdad de Cristo y, sobre todo, les plantea el problema de su vocación. Por tanto, el gran proyecto será ayudar a que los jóvenes desarraigados y rotos se 
conviertan en discípulos y misioneros por medio del descubrimiento de su vocación más honda, a lo cual la Pastoral juvenil debería estar abocada.

Por su parte, esta visión fundamental de las consecuencias culturales del mundo global en América Latina respecto a los jóvenes, obliga al Documento de Aparecida a centrarse en mirar la realidad educativa que debería acompañar y responder a la situación cultural actual. Éste comprueba, en el nivel educativo, un estado de emergencia donde lo principal es la devaluada calidad de la educación, especialmente marcada por un "reduccionismo antropológico" (CELAM, 2007: n. 328) y ético, utilizada como mero objeto mercantil.

Subraya que la educación ha puesto acento en que el educando adquiera conocimientos y habilidades útiles a la producción y al mercado, dejando de lado la formación integral que despliegue los valores humanos y religiosos que permitan fundar vidas y familias con actitudes, virtudes y costumbres solidarias. Esta baja calidad educativa limita el horizonte de vida de los jóvenes, a quienes se les hace más difícil tomar decisiones a largo plazo, volviéndolos indiferentes hacia lo político -lo que se acentúa por la corrupción y el mal ejemplo- llevándolos en muchos casos al suicidio.

Finalmente, la realidad eclesial en relación a los jóvenes es también parte del "ver", tanto en sentido positivo como en sentido negativo. Lo positivo está en "el florecimiento" y la "toma de conciencia" de las pastorales, especialmente la juvenil (CELAM, 2007: n. 99a). El texto sí agradece a los que han alentado la esperanza, entre ellos los jóvenes con sus ideales, y esto puede referirse indirectamente a quienes construyen una de las pastorales más organizadas, estables y duraderas de la iglesia en América Latina, aspecto que Aparecida no pone explícitamente, pero insinúa.

A la vez, se constata un problema de lenguaje en la Iglesia que no se sabe adaptar a la cultura de los jóvenes. El Documento de Aparecida habla de "persistencia" (CELAM, 2007: n. 100d.) es decir de mantención - por tanto, cierto estancamiento- de un lenguaje poco significativo para ellos. No parece hablar de una situación de simple falta de actualización o adaptación sino de la poca significación que tiene nuestra iglesia para la juventud.

En conclusión, Aparecida ve a los jóvenes en Cristo como rostros de víctimas de la situación global, interrogados por el sentido de la vida en un mundo que los echa en la fosa de la pobreza y la violencia, que solo les proporciona el arma ineficiente y autodestructora del individualismo, el narcisismo y la indiferencia. Pero, ellos, tienen la potencialidad de ser nuevos sujetos creadores de una nueva cultura según encuentren el sentido en su búsqueda. Este desafió, que viene de la realidad juvenil así comprendida, conduce a interpelaciones hacia la iglesia que ha de escuchar a esta 
juventud y repensarse según esta realidad, al punto que Aparecida llama a "abandonar las estructuras caducas que ya no favorezcan la transmisión de la fe" (CELAM, 2007: n. 365). De lo contrario, seguirá siendo una iglesia carente de significación para los jóvenes, incapaz de proporcionar respuestas a sus interrogantes.

\section{DE UNA PASTORAL LIBERADORA A UNA PASTORAL REGENERADORA}

Un nuevo modo de comprender la pastoral parece estar siendo necesario a partir de los desafíos de este nuevo mundo juvenil que persiste en la búsqueda de fe o es creyente, y que se manifiesta de dos maneras. Por un lado en los movimientos amplios, aunque ocasionales, de voluntariado, de indignados, de participantes a las jornadas mundiales de juventud, de fervientes cultores de los ídolos del rock y del fútbol, los apasionados jóvenes de los movimientos amplios de revolución democrática en los países de formas dictatoriales en el mundo árabe, de jóvenes que reclaman líderes sabios o abuelos modernos que admiran primero y luego rechazan por traicionar sus promesas, del movimiento juvenil escolar y universitario chileno, del movimiento de los pulpines que derogaron en Perú una ley indigna de empleo juvenil, de los movimientos contra el femicidio, contra la corrupción en varios de nuestros países. Por otro lado, en la vida cotidiana del joven marcada por el mundo global, donde a pesar su dureza por trabajo inestable, desmedido, mal pagado y en una lucha por estudiar y superarse, los jóvenes manejan la red comunicativa como un ambiente que a la vez usan para interactuar y crecer, modificando el modo de aprender que supera la antigua educación y aprenden a resolver las exigencias de identidad e intimidad propias de su edad, y van avanzando hacia la generatividad adulta que los humaniza (Giaccardi, 2016).

El mundo juvenil urbano del presente requiere una nueva atención y una disponibilidad a anchar nuestras perspectivas, como primer paso para una nueva evangelización, debido a que hay una real ruptura con las costumbres, incluso religiosas, los modos y las convicciones de los hombres y mujeres, creyentes y no creyentes del pasado moderno próximo. Una nueva subjetividad juvenil está emergiendo en el mundo; ella hace una nueva experiencia del mundo y de Dios, y comprende experiencialmente en su estilo las cosas humanas y las de la fe, desde su debilidad, pobreza y creencia. Esa subjetividad tiene la forma de un mundo juvenil, que escapa de las categorías que se han usado hasta ahora en pastoral.

La vida juvenil de los últimos años desborda cualquier intento Pastoral debido a que vivimos un mundo en proceso amplio de regeneración desde las bases, donde ha de decidirse las formas regenerativas más adecuadas para la vida del planeta, y donde pueden dominar las formas regeneradoras 
agresivas y elitistas que lo destruyan o reduzcan a la posesión de una minoría. Quizás una pastoral regeneradora de la fe del joven a 50 años de Medellín, que propuso una pastoral liberadora del joven, sea un camino a emprender.

A distancia de cinco décadas, algunos elementos siguen vigentes. La situación oprimida y marginada de los jóvenes que se ha descrito y los peligros que los acechan hacen que sin dudarlo la Iglesia deba contribuir desde la fe cristiana a su liberación de todo lo que los oprime. Pero la liberación tiene dos dimensiones, liberación "de" y liberación "para", y quizás en el año 68 se tenía conciencia de un sujeto juvenil cuajado y organizado que solo necesitaba una sólida formación humana y cristiana para mejorar su conciencia crítica respecto a ideologías que los acechaban. Signo de esto es que los jóvenes se organizaban y eran propensos a formar movimientos juveniles.

La realidad que viven los jóvenes hoy y la respuesta pastoral que se ha de elaborar tiene que ver directamente con la liberación "para", porque se trata de jóvenes a quienes cuesta enormemente forjar esa personalidad, no se organizan en movimientos permanentes, sino con intermitencia, y rehúsan una sólida formación humana y cristiana porque no resisten ningún adoctrinamiento si previamente no han restañado sus heridas. Pero estos jóvenes están buscando regenerar sus vidas en medio de una gran complejidad. Están a la búsqueda de como constituirse en sujetos creadores de futuro, en un mundo donde las finanzas se han encargado de cerrar ese futuro y volverlo un futuro endeudado. La Iglesia ha de insertarse en este proceso con apertura y humildad. Como señaló Francisco en Perú:

Conocer el lenguaje actual de los jóvenes...Como bien supo hacerlo Santo Toribio, no alcanza solamente llegar a un lugar y ocupar un territorio, es necesario poder despertar procesos en la vida de las personas para que la fe arraigue y sea significativa. Y para eso tenemos que hablar su lengua. Es necesario llegar ahí donde se gestan los nuevos relatos y paradigmas, alcanzar con la Palabra de Jesús los núcleos más profundos del alma de nuestras ciudades y de nuestros pueblos (Francisco, 2018b: n. 2).

De modo que el rostro eclesial "pobre, misionero y pascual", que sigue vigente como modelo propuesto para y con los jóvenes, ya que deriva del Evangelio, exige una actualización a los relatos y al proceso de la subjetividad joven que aun requiere de ayuda para superar la confusión y el aislamiento en que la sumerge la aceleración global y la corrupción.

$\mathrm{El}$ aspecto misionero subrayado por Francisco (2013), como la Iglesia en salida, implica tomar la forma de los sujetos a los cuales se va. Los jóvenes reclaman hoy sin gritarlo, una iglesia que los acoja, que les abra 
espacios para ser, cosa que el sistema global impide. No tendrán movimientos grandes y fuertes, pero tienen sus rudimentarios equipos de fútbol, sus asociaciones de bailes folklóricos, y sus juntas para jugar juegos electrónicos. Todas esas juntas son anuncio de lo que quisieran de la Iglesia, un espacio acogedor donde construir su identidad y su intimidad para llegar en mejores condiciones a la generatividad, ser felices y servir a la sociedad.

Desde luego que la fe no es la exacta respuesta a una demanda proveniente de la necesidad, pero no excluye acogerla. Nada de lo humano de los jóvenes le puede ser ajeno. Pero la fe aporta algo novedoso que no es respuesta exacta, pero tampoco respuesta extraña, como si se tratara de un sistema de normas, o una formación "sólida" - que solo puede venir mucho después-, la fe solo puede aportar gratuidad sin medida como experiencia para que los jóvenes puedan comprender como es nuestro Dios "compasivo y misericordioso, lento a la cólera y rico en piedad, que perdona por mil generaciones"...y que no castiga la culpa de los padres en los hijos, por más que el Antiguo testamento diga lo contrario, sino que siempre perdona, "porque es Dios y no hombre"... "y no vendrá con ira" (Os 11, 9).

De allí que la respuesta pastoral ha de ponerse al servicio de la esperanza juvenil buscadora de espacios de regeneración para su propia constitución en sujetos generativos en todos los niveles sociales y en las historias de nuestros países. Esto supone que esa Iglesia "pobre" de Medellín se actualice y rehaga tomando el color y el sabor de la situación golpeada y buscadora del joven, y se relacione con él para compartir su proceso de crecimiento en libertad.

Esto requiere que la Iglesia muestre su disponibilidad a apreciar, valorar y alentar las iniciativas, relatos y procesos juveniles que están en desarrollo fuera del ámbito explícito de los que siempre vienen, para insertarse en ellos y sentir con ellos y asumir sus lenguajes. La Pastoral por tanto reviste un carácter de inserción en aventura misionera dentro de las periferias juveniles, considerando sus esfuerzos como el rostro, la coloración y el sabor que tendrá la iglesia futura, que ha de comenzar en el presente por el diálogo con y desde ellos. Y sin duda esto supone un replanteamiento de las formas racionales y adultas de organizar la vida parroquial y eclesial más amplia. Requiere de una iglesia juvenil de campaña, que inserta en el movimiento intermitente de los jóvenes sencillos y débiles, pero buscadores y hartos de la aclaración.

Es necesario, abrir los espacios ofreciendo en el desarrollo de los aspectos sutiles que actualicen la pascualidad de la Iglesia de Medellín, y que gracias a Francisco (2013) se plasman en la alegría del Evangelio, que no puede ser ajena a las formas de alegría juvenil en medio de la aceleración 
y como respuesta a ella. La rigidez de nuestra manera de alegrarnos debe ser redefinida desde los aportes de lo mejor de las alegrías juveniles, y la iglesia debe asumir sus formas y su lenguaje y expresarse en ellos.

Estos primeros aspectos deberán ser mejor elaborados tras una reflexión teológica de fondo que perciba en los evangelios el aspecto regenerativo del proyecto del Reino de Dios que Jesús predicó. Pero es indudable que mientras es más largo el camino de la liberación de la presión de un sistema económico que en el fondo mata y frustra la esperanza del joven, está más cercana la posibilidad de que la iglesia sea un espacio para regenerarse humanamente, y restañarse de las heridas, no como una purificación sino como una inmersión en las aguas amorosas del útero de Dios, "amorizadas" por el bautismo solidario de Jesús con la humanidad pecadora, que alienta y bendice. Por ello no habrá liberación si no somos ya una iglesia que incluye la regeneración amorosa de Jesús en su forma de ser.

\section{CONCLUSIONES}

Después de recorrer los intentos de la Pastoral Juvenil por evangelizar a los jóvenes en medio de contextos cada vez más complejos, se puede valorar aún más la novedad que aportó Jesús a los jóvenes de su tiempo, y al nuestro, al construir con ellos el proyecto abierto del Reino. Mientras todos los sectores creyentes del antiguo Israel (sacerdotes, fariseos, esenios, Qumran y Juan Bautista) presentan modelos a los cuales los jóvenes debían adscribirse, porque ya estaban hechos y eran Ley, Jesús propuso y propone hoy un proyecto a realizar juntos donde todos tienen lugar, ya que se trata de una aventura abierta por su amor gratuito revelado. ¿Estarán las iglesias diocesanas dispuesta a correr la aventura de esta creatividad?

Por su parte, el recorrido por los cuatro documentos fundamentales de la iglesia Latinoamericana en el tema de la Juventud, permiten derivar algunas conclusiones. Se muestra en los documentos una preocupación por los jóvenes, pero su interés mayor radica en que son, en cierto modo reflejo y reacción, ante las formas que fue adquiriendo la juventud a lo largo de la historia de América Latina en los últimos 50 años. Es explicable que el seguimiento de la iglesia a los jóvenes en Medellín, con una actitud evangélica de apertura y comprensión, humilde y renovadora hacia una juventud crítica y creativa en la historia, desde una perspectiva alentada por el Concilio Vaticano II, se viera disminuida ante un proceso real de dispersión, acentuación de la pobreza y crisis global, que afectó a los jóvenes en su capacidad de subjetividad crítica, y los vertió en acciones cada 
vez más ocasionales y dispersas, según lo señalado en Puebla, hasta prácticamente abandonar su rol de sujeto histórico crítico y propositor de alternativas como lo enfatizó Santo Domingo, pasando a ser una realidad victimal juvenil "rota" y diseminada en un mundo global como lo declaró Aparecida.

Es interesante que el acento tan fuertemente educativo de Aparecida hacia el tema de la juventud se manifieste justamente cuando urge la necesidad de reconstruir al sujeto creador de futuro en nuestro continente. $\mathrm{Y}$ es que hemos ido pasando de una juventud comprometida a una juventud dispersa, luego hemos llegado a unos jóvenes debilitados y rotos, pero sobre todo hoy a un amplio y desafiante mundo juvenil, formado por pocos jóvenes fuertes y una amplia mayoría de jóvenes debilitados y pobres, pero comunicados y globales, que van curando sus heridas y aprendiendo a vivir como peces en las aguas movedizas del mar global. A esto se agrega, lo que ya mencionaba Aparecida del problema "endémico de la corrupción" (CELAM, 2007: n. 507) donde las instituciones ya no viven su misión de servir, proteger, buscar el bien común o abrir oportunidades, esto genera decepción, incredulidad y desesperanza en los jóvenes quienes no se sienten motivados de participar en experiencias asociativas.

Esto descoloca a la Iglesia y a su pastoral. Es demasiado mundo juvenil para tan estrecha iglesia y pastoral, a lo cual se añade los problemas internos de crisis institucional de la iglesia, es decir, no sólo aparece una sociedad adversa con los jóvenes, sino que ahora la iglesia puede ser un espacio inseguro para ellos. Sin embargo, no dialogar es encerrarse y destruir la santa ocasión que nos ofrece ese mundo para evangelizar.

Mientras tanto, habrá que considerar que la ausencia de eficacia eclesial respecto al asunto de la juventud es parte de la crisis más grande en que se debate nuestra Iglesia Católica, ante un mundo que nos sobrepasa, y habrá que ser conscientes de que una buena solución a esta crisis es mantener la actitud del Concilio Vaticano II, la de Medellín y la de Jesús con los jóvenes en los evangelios. Aparecida va en este camino, ojalá no sea distorsionado. En esa línea, los intentos de revitalización de la Pastoral Juvenil de la Iglesia de América Latina, no pueden vivirse sin hacer una opción clara a favor de esa actitud y en distancia a la línea adscriptiva que trata a los jóvenes como objeto que no tienen nada que aportar.

La ocasión del Sínodo de Jóvenes 2018, será un encuentro extraordinario para profundizar sobre la renovación de la pastoral juvenil, dado que el tema elegido, "Los jóvenes, la fe y el discernimiento vocacional", toca la médula del problema en un mundo en donde se pretende usar al joven solo para producir y ganar, dejando de lado sus capacidades, sus habilidades, y su vocación, donde se quiere que el joven solo piense en consumir, y no en discernir el sentido de las cosas para actuar. Renovar seriamente 
la pastoral juvenil implicará superar un modelo doctrinario que más bien se sustituya con un modelo de acompañamiento participativo de los jóvenes para renacer a una vida adulta generativa y creadora de una alternativa de mundo vivible.

\section{REFERENCIAS}

-Atilano, J. (2004). Pistas para un diálogo entre la teología y las culturas juveniles. Christus (741), 17-23.

-Bacq, Ph. \& Theobald, C. (2011). Una nueva oportunidad para el evangelio. Hacia una pastoral de engendramiento. Bilbao: Desclee.

-Beauchamp, P. \& Vasse, D. (1992). La violencia en la biblia: Navarra: Verbo divino.

-Busto, J.R. (1992). La justicia es inmortal. Una lectura del libro de la Sabiduría de Salomón. Santander: Sígueme.

-Castillo, C. (2003). Joven, a ti te Digo, Levántate. Perspectivas Sobre los Jóvenes en el Nuevo Testamento. Medellín, 29(113), 107-126.

-CELAM (1968). Medellin. Segunda Conferencia general del Episcopado Latinoamericano. Bogotá: Celam.

-CELAM (1979). Puebla. Tercera Conferencia general del Episcopado Latinoamericano. Bogotá: Celam.

-CELAM (1992). Santo Domingo. Cuarta Conferencia general del Episcopado Latinoamericano. Bogotá: Celam.

-CELAM (2007). Aparecida. Quinta Conferencia general del Episcopado Latinoamericano. Bogotá: Celam.

-Curro, S. (2011). Il senso umano del credere, Pastorale dei giovani e sfida antropológica. Torino: ELLEDICI

-Espitia, M. (2008). Soy joven, creo en Dios...zy que?, Miradas de teología y espiritualidad juvenil. Bogotá: Códice.

-Francisco (2013). Evangelii Gaudium. Lima: San Pablo.

-Francisco (2018a). Conferencia de prensa del Santo padre durante el vuelo de regreso a Roma. Disponible en http://w2.vatican.va/content/francesco/es/speeches/2018/january/documents/papa-francesco_20180121_peru-voloritorno.html

-Francisco (2018b). Encuentro con los obispos discurso del santo padre Palacio Arzobispal (Lima). Disponible en http://w2.vatican.va/content/francesco/es/speeches/2018/january/documents/papa-francesco_20180121_peru-lima-vescovi.html

-Giaccardi, Ch. (2016). Jóvenes, medios audiovisuales y desafíos educativos. Misión Juvenil (468-469), 95-100.

-Gutiérrez, G. (1986). Hablar de Dios desde el sufrimiento del inocente, una reflexión sobre el libro de Job. Lima: RIMAC.

-Harari, N.Y. (2016). Homo Deus, breve historia del mañana. Debate, Penguin Random House. Barcelona: Grupo Editorial S.A.U.

-Magatti, M. (2017). Cambio di paradigma, uscire dalla crisi pensando al futuro. Milano: Feltrinelli. 
-Pikaza, X. (1993). Antropología bíblica. Del árbol del juicio al sepulcro de pascua. Salamanca: Sígueme.

-Rossano, S. (2017). Pastorale Giovanile 1. Evangelizzazione e educazione dei giovani. Un percorso teorico-pratico. Roma: LAS.

-Saulnier, C. (1985). La crisis macabea. Navarra: Verbo divino.

-Silva, C. (1993). Que 25 años no es nada, la opción preferencial por los jóvenes en las conferencias generales del episcopado latinoamericano. Última década (1), 1-18.

-Sínodo de los Obispos (2018). Los jóvenes, la fe y el discernimiento vocacional, Instrumentum laboris. Disponible en http://www.synod2018.va/content/synod2018/es/documentos/instrumentum-laboris-para-el-sinodo-sobre-losjovenes-2018.html

-Tassin, C. (1987). El judaísmo, desde el destierro hasta el tiempo de Jesús. Navarra: Verbo divino.

-Vilchez, J. (1994). Eclesiastés o Qobelet. Navarra: Verbo divino.

-Vilchez, J. (1995). Eclesiástico. Navarra: Verbo divino.

Sumario: Introducción; 1. Los jóvenes como víctimas de la corrupción en las estructuras sociales y eclesiales en tiempos de Jesús; 2. Los jóvenes frente a las estructuras de pecado denunciadas por las Conferencias Generales del Episcopado Latinoamericano; 2.1. Medellín; 2.2. Puebla; 2.3. Santo Domingo; 2.4. Aparecida; 3. De una pastoral liberadora a una pastoral regeneradora; Conclusiones; Referencias. 